\title{
Molecular mechanisms underlying mangiferin-induced apoptosis and cell cycle arrest in A549 human lung carcinoma cells
}

\author{
WEI SHI ${ }^{*}$, JIAGANG DENG $^{2 *}$, RONGSHENG TONG $^{3}$, YONG YANG $^{3}$, XIA HE $^{3}$, JIANZHEN LV $^{2}$, \\ HAILIAN WANG ${ }^{4}$, SHAOPING DENG ${ }^{4}$, PING QI ${ }^{1}$, DINGDING ZHANG ${ }^{5}$ and YI WANG $^{3}$ \\ ${ }^{1}$ Department of Pediatrics, Sichuan Academy of Medical Science and Sichuan Provincial People's Hospital, \\ Chengdu, Sichuan 610072; ${ }^{2}$ Guangxi Province Key Laboratory, Guangxi University of Chinese Medicine, \\ Nanning, Guangxi 530200; ${ }^{3}$ Department of Pharmacy; ${ }^{4}$ Institute of Organ Transplantation, and \\ ${ }^{5}$ Sichuan Academy of Medical Science and Sichuan Provincial People's Hospital, Chengdu, Sichuan 610072, P.R. China
}

Received March 19, 2015; Accepted January 18, 2016

DOI: $10.3892 / \mathrm{mmr} .2016 .4947$

\begin{abstract}
Mangiferin, which is a C-glucosylxanthone (1,3,6,7-tetrahydroxyxanthone-C2- $\beta$ - $D$-glucoside) purified from plant sources, has recently gained attention due to its various biological activities. The present study aimed to determine the apoptotic effects of mangiferin on A549 human lung adenocarcinoma cells. In vitro studies demonstrated that mangiferin exerted growth-inhibitory and apoptosis-inducing effects against A549 cells. In addition, mangiferin exhibited anti-tumor properties in A549 xenograft mice in vivo. Mangiferin triggered $\mathrm{G}_{2} / \mathrm{M}$ phase cell cycle arrest via downregulating the cyclin-dependent kinase 1-cyclin B1 signaling pathway, and induced apoptotic cell death by inhibiting the protein kinase $\mathrm{C}$-nuclear factor- $\kappa \mathrm{B}$ pathway. In addition, mangiferin was able to enhance the antiproliferative effects of cisplatin on A549 cells, thus indicating the potential for a combined therapy. Notably, mangiferin exerted anticancer effects in vivo, where it was able to markedly decrease the volume and weight of subcutaneous tumor mass, and expand the lifespan of xenograft mice. The present study clarified the molecular mechanisms underlying mangiferin-induced antitumor activities, and suggested that mangiferin may be considered a potential antineoplastic drug for the future treatment of cancer.
\end{abstract}

Correspondence to: Dr Yi Wang, Department of Pharmacy, Sichuan Academy of Medical Science and Sichuan Provincial People's Hospital, 32 West Ring Road, Chengdu, Sichuan 610072, P.R. China E-mail:w_yi@yahoo.com

Dr Ping Qi, Department of Pediatrics, Sichuan Academy of Medical Science and Sichuan Provincial People's Hospital, 32 West Ring Road, Chengdu, Sichuan 610072, P.R. China

E-mail: 917964967@qq.com

${ }^{*}$ Contributed equally

Key words: mangiferin, cdc2-cyclin B1 signaling pathway, PKC-NF- $\kappa$ B pathway

\section{Introduction}

Mangiferin is isolated from the leaves, stem bark, fruit peel and root of Mangifera indica L. and other herbal species (1). Previous studies have reported that mangiferin exerts numerous beneficial biological effects, including antioxidant (2), antitumor (3), antibacterial, antiviral and immunomodulatory activities (4). In addition, previous studies have indicated that mangiferin exerts markedly antineoplastic effects toward prostate cancer (5), colon cancer (6,7), leukemia (5,8-11), and lung cancer $(5,6,11)$. It has previously been suggested that mangiferin is able to markedly inhibit the proliferation of K562 leukemia cells, and induce cell apoptosis via the downregulation of nuclear factor (NF)- $\kappa \mathrm{B}$ activity (9). Furthermore, mangiferin has been demonstrated to inhibit telomerase activity of K562 cells in a time- and- dose-dependent manner, induce apoptosis, and upregulate the mRNA and protein expression of Fas (10).

Cancer is a complex genetic disease that results from mutations in oncogenes or tumor suppressor genes, thus leading to altered signaling pathways (11). It is widely acknowledged that normal cells are able to check and repair DNA damage in response to external stimuli, otherwise affected cells would undergo cell death, by mechanisms including apoptosis and autophagy, if the DNA lesion was irreparable (12). Dysfunctional methods of repair or insufficient elimination of damaged cells will eventually lead to malignant transformation; therefore, programmed cell death modulation may function as a potential target of cancer treatment by which damaged and potentially deleterious cells could be cleared. Apoptotic cells have long been observed to display a series of morphological characteristics, including nuclear and cytoplasmic shrinkage, membrane blebbing, and shattering (13-15), thus suggesting the existence of common pathways involved in apoptotic cell death. The caspase family has been identified as a common pathway that is essential for the progression of apoptosis. Usually, but not exclusively, apoptosis is associated with the activation of caspase, and both the extrinsic and intrinsic apoptotic pathways finally converge to a common process, which initiates a caspase cascade (16).

The present study demonstrated that mangiferin was able to trigger $\mathrm{G}_{2} / \mathrm{M}$ phase cell cycle arrest via downregulating the 
cyclin-dependent kinase 1 (cdc2)-cyclin B1 signaling pathway, and induce apoptosis by inhibiting the protein kinase $\mathrm{C}$ (PKC)-NF- $\mathrm{KB}$ pathway in A549 human lung carcinoma cells. In addition, mangiferin exerted anticancer effects in vivo, where it was able to significantly decrease the volume and weight of subcutaneous tumor mass, and expand the lifespan of A549 xenograft mice.

\section{Materials and methods}

Reagents. Mangiferin was purchased from Shanghai Pureone Biological Technology Co., Ltd. (Shanghai, China). The purity of mangiferin was $>95 \%$, and the chemical structure is presented in Fig. 1A. The A375 melanoma cells, HepG2 and 7721 hepatocellular carcinoma cells, MCF-7 breast carcinoma cells, non-small cell lung cancer A549 cells, glioblastoma U87 cells and human embryonic lung fibroblast (HELF) cells were purchased from American Type Culture Collection (Manassas, VA, USA), and the normal human embryonic lung fibroblast (HELF) cell line was purchased from The Cell Bank of the Chinese Academy of Sciences (Shanghai, China). Fetal bovine serum (FBS) was purchased from Gibco (Thermo Fisher Scientific, Inc., Waltham, MA, USA). 3-(4,5-dimetrylthiazol-2-yl)-2,5-diphenyltetrazolium bromide (MTT), z-VAD-fmk (pan-caspase inhibitor), z-DEVD-fmk (caspase-3 inhibitor), z-LEHD-fmk (caspase-9 inhibitor), propidium iodide (PI) and rhodamine-123 were purchased from Sigma-Aldrich (St. Louis, MO, USA).

Cell culture. A549 human lung adenocarcinoma cells were cultured in Dulbecco's modified Eagle's medium (DMEM; Gibco; Thermo Fisher Scientific, Inc.) supplemented with $10 \%$ FBS, $100 \mathrm{mg} / \mathrm{ml}$ streptomycin (Thermo Fisher Scientific, Inc.), $100 \mathrm{U} / \mathrm{ml}$ penicillin (Thermo Fisher Scientific, Inc.) and $0.03 \%$ L-glutamine (Sigma-Aldrich) at $37^{\circ} \mathrm{C}$ in a humidified atmosphere containing $5 \% \mathrm{CO}_{2}$. In order to generate an in vivo cancer model, a suspension of A549 cultured human lung adenocarcinoma cells $\left(1.0 \times 10^{7}\right.$ cells) was inoculated into the neck of 3-month-old male nude mice (Shanghai Laboratory Animal Research Center, Shanghai, China). The HELF cells, which were used in the corresponding control group, were also cultured under the same conditions. For the inhibition of NF- $\kappa \mathrm{B}, 100 \mu \mathrm{M}$ PDTC (Sigma-Aldrich) was incubated with the cells for $1 \mathrm{~h}$. For inhibition of PKC, $2 \mu \mathrm{M}$ staurosporine (Sigma-Aldrich) was incubated with the cells for $1 \mathrm{~h}$.

MTT colorimetric assay. A549 cells at logarithmic growth phase were seeded in a 96 -well plate $\left(3 \times 10^{4}\right.$ cells per well) and incubated at $37^{\circ} \mathrm{C}$ for $24 \mathrm{~h}$. Various concentrations of mangiferin $(12.5,25,50$ and $100 \mu \mathrm{g} / \mathrm{ml})$ were added to the cells, which were incubated for a further $12,24,36$ and $48 \mathrm{~h}$. The control group was treated with phosphate-buffered saline (PBS; Sigma-Aldrich). Subsequently, $0.05 \mathrm{mg}$ MTT (10 $\mu 1$ of $5 \mathrm{mg} / \mathrm{ml}$ ) was added to each well and incubated at $37^{\circ} \mathrm{C}$ for $4 \mathrm{~h}$, after which the medium was removed and the plate was thoroughly agitated for $1 \mathrm{~h}$. Finally, termination buffer (SDS-HCl) was added to each well and incubated for $4 \mathrm{~h}$ at room temperature. The absorbance was measured at a wavelength of $570 \mathrm{~nm}$ using a spectrophotometer (Model 3550 Microplate Reader; Bio-Rad Laboratories, Inc., Hercules, CA, USA). Cell viability was determined using the following equation: Cell viability $(\%)=[\mathrm{OD} 570 \mathrm{~nm}(\mathrm{drug}) / \mathrm{OD} 570 \mathrm{~nm}$ (control) $] \times 100 \%$. OD indicates optical density.

Observations of cell morphological changes. A549 and HELF cells were seeded into 6-well culture plates at a density of $4 \times 10^{5}$ cells/well in DMEM containing 10\% FBS, and were cultured for $24 \mathrm{~h}$. The control group was treated with $0.05 \%$ dimethyl sulfoxide (DMSO; Sigma-Aldrich), whereas the mangiferin group was treated with $25 \mu \mathrm{g} / \mathrm{ml}$ mangiferin. Hoechst 33342 (Sigma-Aldrich) staining was used to further detect the presence of viable cells. Briefly, cells were fixed with $4 \%$ paraformaldehyde (Sigma-Aldrich) for $30 \mathrm{~min}$ at room temperature following a $24 \mathrm{~h}$ incubation with either mangiferin or $0.05 \%$ DMSO. The cells were then washed twice with PBS, and Hoechst $33342(5 \mu \mathrm{g} / \mathrm{ml})$ was added to the cells for $15 \mathrm{~min}$, after which the cells were washed and analyzed immediately using a fluorescence microscope (Olympus ix73; Olympus Corporation, Tokyo, Japan).

Measurement of cell cycle progression and sub- $G_{I}$ cells. A549 cells treated with $25 \mu \mathrm{g} / \mathrm{ml}$ mangiferin or $0.05 \%$ DMSO at $37^{\circ} \mathrm{C}$ for $12,24,36$ and $48 \mathrm{~h}$ were harvested and washed with $0.01 \mathrm{M}$ cold PBS. The cells were then fixed with $70 \%$ ethanol (Sigma-Aldrich) and were incubated at $4^{\circ} \mathrm{C}$ for $24 \mathrm{~h}$. Cell pellets were stained with $1 \mathrm{ml}$ PI solution, which consisted of $65 \mu \mathrm{g} / \mathrm{ml}$ PI and $50 \mu \mathrm{g} / \mathrm{ml}$ RNase (Sigma-Aldrich) in $0.01 \mathrm{M}$ PBS for $30 \mathrm{~min}$ at $37^{\circ} \mathrm{C}$. The percentage of cells at various phases of the cell cycle and undergoing apoptosis were evaluated using FACSCalibur flow cytometry (BD Biosciences, Franklin Lakes, NJ, USA) and analyzed by CellQuest software (version 5.1; Becton Dickinson, San Jose, CA, USA). In order to further classify the proportion of early and late apoptotic mangiferin-treated A549 cells, Annexin V-fluorescein isothiocyanate (FITC)/PI double staining assay was performed using the Annexin V-FITC Apoptosis Detection kit (BD Pharmingen, San Diego, CA, USA), according to the manufacturer's protocol.

Caspase assay. A549 cells were seeded into a 6-well culture plate at a density of $4 \times 10^{5}$ cells/well for $16 \mathrm{~h}$. Subsequently, the cells were treated with or without $100 \mu \mathrm{M} \mathrm{z}$-VAD-fmk (pan-caspase inhibitor), $50 \mu \mathrm{M}$ z-DEVD-fmk (caspase-3 inhibitor) and $50 \mu \mathrm{M} \mathrm{z}$-LEHD-fmk (caspase-9 inhibitor) for $2 \mathrm{~h}$ at $37^{\circ} \mathrm{C}$. The cells were then treated with $25 \mu \mathrm{g} / \mathrm{ml}$ mangiferin for $24 \mathrm{~h}$, and the MTT assay was performed as previously described. In addition, caspase-3 activity was further measured using a colorimetric assay kit (cat. no. k106-100; BioVision Inc., Milpitas, CA, USA), according to the manufacturer's protocol. To inhibit autophagy, $5 \mathrm{mM}$ 3-methyladenine (3-MA; Sigma-Aldrich) was incubated with the cells for $6 \mathrm{~h}$. Furthermore, A549 cells underwent immunofluorescent staining of caspase-3. Briefly, A549 cells were cultured overnight in a 6-well plate until they reached $90 \%$ confluence. The cells were then treated with $25 \mu \mathrm{g} / \mathrm{ml}$ mangiferin for 0,12 and $24 \mathrm{~h}$, and were fixed and stained with polyclonal rabbit anti-cleaved-caspase-3 antibody (cat. no. 9661; Cell Signaling Technology, Inc., Beverly, MA, USA). FITC-conjugated s goat anti-rabbit IgG secondary antibody (cat. no. 11-095-003; Jackson ImmunoResearch, 
West Grove, PA, USA) was further applied to the cells, which were observed under a fluorescent microscope (Olympus ix73; Olympus Corporation).

Detection of mitochondrial membrane potential. Mitochondrial membrane potential was measured using the fluorescent dye rhodamine-123. After treatment with $25 \mu \mathrm{g} / \mathrm{ml}$ mangiferin for $12,24,36$ and $48 \mathrm{~h}$, the cells were collected and suspended in $1 \mathrm{ml}$ PBS containing $1 \mu \mathrm{g} / \mathrm{ml}$ rhodamine- 123 for $15 \mathrm{~min}$ at $37^{\circ} \mathrm{C}$. The fluorescence intensity of the cells was analyzed by BD FACS Aria II using BD FACS Diva software (BD Biosciences, San Jose, CA, USA).

Western blot analysis. A549 cells were treated with $25 \mu \mathrm{g} / \mathrm{ml}$ mangiferin for 12, 24, 36 and $48 \mathrm{~h}$, and both adherent and floating cells were collected. The cell pellets were resuspended in lysis buffer and lysed at $4^{\circ} \mathrm{C}$ for $15 \mathrm{~min}$. The lysis buffer consisted of $50 \mathrm{mmol} / 1$ Hepes (pH 7.4), 1\% Triton X-100, $2 \mathrm{mmol} / \mathrm{l}$ sodium orthovanadate, $100 \mathrm{mmol} / 1$ sodium fluoride, $1 \mathrm{mmol} / \mathrm{l}$ edetic acid, $1 \mathrm{mmol} / 1$ phenylmethylsulfonyl fluoride, $10 \mathrm{mg} / \mathrm{l}$ aprotinin and $10 \mathrm{mg} / 1$ leupeptin (all Sigma-Aldrich). Following centrifugation at $12,000 \mathrm{x}$ g for $15 \mathrm{~min}$ at $4^{\circ} \mathrm{C}$, the protein content of the supernatant was determined using the Bio-Rad Bradford Protein Assay (Bio-Rad Laboratories, Inc.). A mitochondria isolation kit (cat. no. 89874; Thermo Fisher Scientific, Inc.) was applied for the isolation of mitochondrial protein. Equal quantities of total protein $(20 \mu \mathrm{g})$ were separated by $4-12 \%$ NuPAGE $^{\circledR}$ Bis-Tris gels (Thermo Fisher Scientific, Inc.) and were transferred to polyvinylidene difluoride membranes (EMD Millipore, Bedford, MA, USA). The membranes were soaked in blocking buffer ( $5 \%$ bovine serum albumin; Sigma-Aldrich), and the proteins of interest were detected using the following primary antibodies: Rabbit polyclonal pro-caspase-3 (cat. no. sc-7148; 1:1,000 dilution), rabbit polyclonal cleaved caspase-3 (cat. no. sc-22171-R; 1:500 dilution), mouse monoclonal pro-caspase-9 (cat. no. sc-56073; 1:1,000 dilution), goat polyclonal cleaved caspase-9 (cat. no. sc-22182; 1:1,000 dilution), rabbit polyclonal Bax (cat. no. sc-493; 1:500 dilution), rabbit polyclonal Bcl-2 (cat. no. sc-492; 1:1,000 dilution), mouse monoclonal Bcl-XL (cat. no. sc-8392; 1:1,000 dilution), rabbit polyclonal PARP (cat. no. sc-7150; 1:1,000 dilution), rabbit polyclonal cytochrome $c$ (cat. no. sc-7159; 1:1,000 dilution), rabbit polyclonal Prohibitin (cat. no. sc-28259; 1:2,000 dilution), rabbit polyclonal PKC (cat. no. sc-208; 1:1,000 dilution), mouse monoclonal cdc2 (cat. no. sc-54; 1:1,000 dilution), rabbit polyclonal NF- $\mathrm{B}$ (cat. no. sc-109; $1: 500$ dilution) and mouse monoclonal $\beta$-actin (cat. no. sc-47778; 1:5,000 dilution) purchased from Santa Cruz Biotechnology, Inc. (Santa Cruz, CA, USA). Horseradish peroxidase (HRP)-conjugated goat anti-mouse IgG secondary antibody (cat. no. 11-035-003) and HRP-conjugated mouse anti-rabbit IgG (cat. no. 211-035-109) were purchased from Jackson ImmunoResearch Laboratories. The membranes were incubated with primary antibody overnight at $4^{\circ} \mathrm{C}$ and then washed with TBS buffer containing $0.1 \%$ Tween-20 (Sigma-Aldrich). Secondary antibody was incubated at room temperature for $1 \mathrm{~h}$ and washed with TBS buffer containing $0.1 \%$ Tween-20. The blots were visualized using enhanced chemiluminescence (GE Healthcare, Arlington Heights, IL, USA).
Acute toxicity testing. Acute toxicity testing was performed to determine the median lethal dose $\left(\mathrm{LD}_{50}\right)$ of mangiferin. After $16 \mathrm{~h}$ fasting, 80 male nude C57BL mice were randomly divided into eight groups ( $\mathrm{n}=10 \mathrm{mice} / \mathrm{group})$. Graded doses of mangiferin, dissolved in PBS (20, 50, 100, 200, 400, 600, 1,000 and $2,000 \mathrm{mg} / \mathrm{kg}$ ), were administered intraperitoneally to the mice; the average volume injected was $0.3 \mathrm{ml}$. All mice were allowed ad libitum access to food and water, and the mortality in each group was assessed 24, 48 and $72 \mathrm{~h}$ after administration of mangiferin. Percentage mortality in each group was calculated and plotted against $\log _{10}$ mangiferin dose. A regression line was fitted by the method of least squares, and confidence limits for $\mathrm{LD}_{50}$ values were calculated. Animal handling was in accordance with the Ethics Committee of Sichuan Academy of Medical Science \& Sichuan Provincial People's Hospital (Medical School, University of Electronic Science and Technology of China, Chengdu, China), and all mice were kept under a $12 \mathrm{~h}$ light/dark cycle with ad libitum access to food and water, which is in compliance with individually ventilated cages requirements at the Sichuan Academy of Medical Science \& Sichuan Provincial People's Hospital.

Animal group and in vivo xenograft study. A total of 50 3-month-old male nude C57BL/6 mice were randomly divided into five groups: Blank control group, mice administered PBS following injection with A549 cells; high-dose mangiferin group, mice administered $100 \mathrm{mg} / \mathrm{kg}$ mangiferin following injection with A549 cells; medium-dose mangiferin group, mice administered $50 \mathrm{mg} / \mathrm{kg}$ mangiferin following injection with A549 cells; low-dose mangiferin group, mice administered $10 \mathrm{mg} / \mathrm{kg}$ mangiferin following injection with A549 cells; positive control (cisplatin) group, mice administered cisplatin (10 mg/kg; Sigma-Aldrich) following injection with A549 cells. Mangiferin (10, 50 and $100 \mathrm{mg} / \mathrm{kg}$ ) was intraperitoneally injected into the mice, and the therapy lasted for 2 weeks. The measurement and calculation of relative tumor volume, survival rate, inhibitory rate and body weight was performed as previously described (17). Briefly, tumor volume was determined using caliper measurements, according to the following formula: $T_{v o l}=$ length $\mathrm{x}$ width $\mathrm{x}$ depth $\mathrm{x} 0.5$. Relative tumor volume (RTV) was calculated as relative increase or decrease in mean tumor volume from initiation of treatment $\left(\mathrm{V}_{0}\right)$ up to value at a given time $\left(V_{t}\right)$ and $R T V=V_{t} / V_{0}$. Inhibitory rate of tumor volume was determined as follows: Tumor volume inhibition rate $=\left(V_{\text {control }} \times V_{t}\right) / V_{\text {control }} \times 100 \%$. After 14 days of treatment, the mice were sacrificed by cervical dislocation, and subcutaneous tumour mass was determined. Inhibitory rate of tumour weight was determined as follows: Tumor weight inhibition rate $=\left(W_{\text {control }}-W_{t}\right) / W_{\text {control }} \times 100 \%$.

Statistical analysis. All data are presented as the mean \pm standard error of the mean from at least three independent experiments. Data analysis was performed using GraphPad Prism 5.0 software (Graphpad Software, Inc., La Jolla, CA, USA). Statistical significance was determined by Student's t-test for Figs. 3A, C, E and 4A, 5A and 6A. Statistical significance was also determined by two-way analysis of variance for Figs. 1C, 2C, 6B and 6D. The survival data (Fig. 6C) were analyzed using the Kaplan-Meier method. 


\section{Results}

Cytotoxic effects of mangiferin on A549 cells. The growth inhibitory effects of mangiferin were assessed using the MTT assay on the following human cancer cell lines: Caco-2 colon carcinoma cells, HeLa cervical carcinoma cells, A375 melanoma cells, HepG2 and 7721 hepatocellular carcinoma cells, MCF-7 breast carcinoma cells, non-small cell lung cancer A549 cells and glioblastoma U87 cells. The half maximal inhibitory concentration values were $33,45,54,46,28,48,25$ and $32 \mu \mathrm{g} / \mathrm{ml}$, respectively (Fig. 1B). These results indicate that mangiferin was more sensitive to A549 non-small cell lung cancer cells; therefore, A549 cells were chosen for further exploration.

To further assess the antitumor properties of mangiferin in A549 cells, an MTT assay was performed. Mangiferin was revealed to induce A549 cell death in a dose-dependent manner. Various doses of mangiferin $(0-100 \mu \mathrm{g} / \mathrm{ml})$ were added to the culture medium of A549 cells, and even a very low dose of mangiferin $(12.5 \mu \mathrm{g} / \mathrm{ml})$ exhibited inhibitory effects on cell proliferation (Fig. 1C). After incubation with $25 \mu \mathrm{g} / \mathrm{ml}$ mangiferin, the inhibitory rate reached $\sim 50 \%$, and following treatment with a higher dose of mangiferin $(100 \mu \mathrm{g} / \mathrm{ml})$, the inhibitory rate reached $>60 \%$ at $12 \mathrm{~h}$. These results suggest that the inhibitory efficiency of mangiferin is comparatively high. Treatment with cisplatin $(12.5,25,50$ or $100 \mu \mathrm{g} / \mathrm{ml})$ exerted a significant inhibitory effect on the proliferation of A549 cells, and $12.5 \mu \mathrm{g} / \mathrm{ml}$ cisplatin resulted in $~ 50 \%$ proliferation inhibition at $24 \mathrm{~h}$ (Fig. 1C). Subsequently, a series of doses of cisplatin in combination with $25 \mu \mathrm{g} / \mathrm{ml}$ mangiferin (cisplatin $+25 \mu \mathrm{g} / \mathrm{ml}$ mangiferin) were used to treat A549 cells, and cell viability was assessed by MTT assay, at various time points. Cisplatin $+25 \mu \mathrm{g} / \mathrm{ml}$ mangiferin synergistically inhibited the proliferation of A549 cells (Fig. 1C); $12.5 \mu \mathrm{g} / \mathrm{ml}$ cisplatin in combination with $25 \mu \mathrm{g} / \mathrm{ml}$ mangiferin resulted in $50 \%$ inhibitory ratio of A549 cells at $12 \mathrm{~h}$, thus indicating that mangiferin treatment may amplify the antineoplastic effects of cisplatin on A549 cells.

Observation of cell morphology and cell cycle distribution. Subsequently, A549 cells were treated with 0.05\% DMSO, mangiferin alone, or mangiferin plus cisplatin, and cell morphology was observed under phase contrast microscopy (Fig. 2A, upper channel). Markedly less viable cells were observed following mangiferin treatment, and even fewer cells survived mangiferin plus cisplatin treatment. This result was determined by Hoechst 33342 staining, which marks viable cells. Conversely, treatment with $25 \mu \mathrm{g} / \mathrm{ml}$ mangiferin did not result in apparent apoptotic morphology in non-cancerous HELF cells following a $48 \mathrm{~h}$ treatment (Fig. 2B). These results suggest that mangiferin may selectively induce A549 cells apoptosis, but may not trigger apoptosis of normal HELF cells. In addition, cell cycle analysis was performed to determine cell cycle distribution of A549 cells following treatment with mangiferin. Statistical analysis of the number of cells at sub- $G_{1}, G_{0} / G_{1}, S$ and $G_{2} / M$ phase indicated that more cells were arrested in sub- $\mathrm{G}_{1}$ phase after mangiferin treatment, thus suggesting that mangiferin may induce apoptosis of A549 cells in a time-dependent manner. Furthermore, $\mathrm{G}_{2} / \mathrm{M}$ phase arrest was observed in the mangiferin-treated cells (Fig. 2C). Annexin
V-FITC and PI double staining was performed to classify the number of viable cells (Annexin V-/PI-), early apoptotic cells (Annexin V+/PI-), late apoptotic cells (Annexin V+/PI+) and necrotic cells (Annexin V-/PI+). As shown in Fig. 2D, following treatment with $25 \mu \mathrm{g} / \mathrm{ml}$ mangiferin, the percentage of early apoptotic cells and late apoptotic cells were gradually enhanced with increasing time. These results indicate that mangiferin induces apoptotic cell death in A549 cells.

Mangiferin induces apoptosis in a caspase-dependent manner. To evaluate whether mangiferin-induced cell death was dependent on the caspase pathway, various caspase inhibitors were applied as shown in Fig. 3A. After a $24 \mathrm{~h}$ incubation with mangiferin plus caspase inhibitors or PBS control, cell inhibition of each group was quantified. As demonstrated by Fig. 3A, mangiferin-induced cell growth inhibition was completely suppressed by the addition of pan-caspase, caspase- 3 and caspase-9 inhibitors, thus indicating that mangiferin induced cell apoptosis in a caspase-dependent manner. Furthermore, western blot analyses demonstrated that following treatment with $25 \mu \mathrm{g} / \mathrm{ml}$ mangiferin, caspase-3 and caspase-9 were cleaved, since procaspase- 3 and procaspase- 9 expression was decreased whereas cleaved caspase- 3 and cleaved caspase- 9 expression was increased with the duration of mangiferin treatment. In addition, upregulation of proapoptotic B-cell lymphoma $(\mathrm{Bcl})$ 2-associated $\mathrm{X}(\mathrm{Bax})$ protein, and downregulation of anti-apoptotic Bcl-2 and Bcl-extra large (xL) proteins was also detected following mangiferin treatment. Treatment with $25 \mu \mathrm{g} / \mathrm{ml}$ mangiferin also led to enhanced cleavage of poly ADP-ribose polymerase (PARP) in a time-dependent manner (Fig. 3B).

To further verify that mangiferin-induced apoptosis is dependent on the caspase pathway, caspase-3 activity was assessed. As shown in Fig. 3C, following treatment with the autophagic inhibitor 3-methyladenine $(5 \mathrm{mM})$, $25 \mu \mathrm{g} / \mathrm{ml}$ mangiferin significantly increased caspase- 3 activity in a time-dependent manner, thus indicating that mangiferin-induced apoptosis occurs via the activation of common apoptotic executors such as caspase-3. Furthermore, immunofluorescent staining of cleaved caspase-3 was conducted (Fig. 3D) and the number of cells positively stained for cleaved caspase-3 was manually counted. Statistical analysis of the percentage of cleaved caspase-3-positive cells indicated that the longer the duration of mangiferin treatment, the higher proportion of cleaved caspase-3-positive cells (Fig. 3E). These results confirm that mangiferin increased the activities of caspase- 3 and caspase- 9 in a time-dependent manner.

Mangiferin induces apoptosis via the mitochondrial pathway. To further investigate whether mangiferin induced apoptosis via the mitochondrial pathway, rhodamine 123 staining assay was performed to measure the integrity of mitochondrial membranes. As indicated in Fig. 4A, mangiferin decreased the fluorescence intensity of rhodamine 123 in a time-dependent manner (control group, 91\%; 12 h group, 82\%; 24 h group, $65 \%$; 36 h group, 46\%; 48 h group, 23\%; $\mathrm{P}<0.05, \mathrm{n}=3$ ). In addition, detection of cytochrome $c$ in the cytosol and mitochondria suggested that the amount of cytochrome $c$ in the mitochondria of the mangiferin-treated cells was decreased. Furthermore, the amount of cytochrome $c$ in the cytosol of 
A

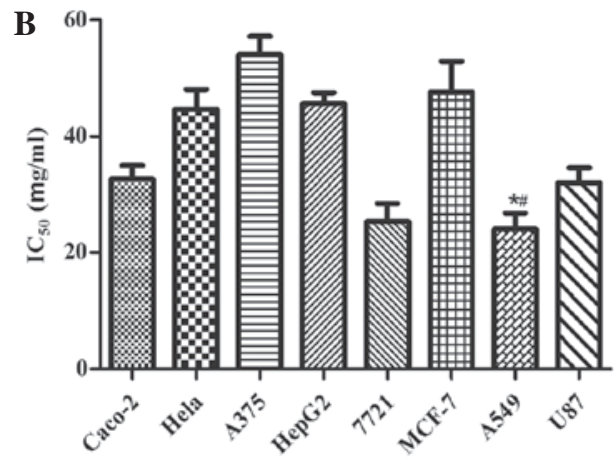

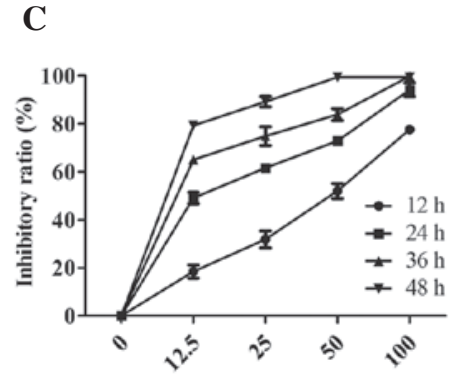

Concentration of mangiferin $(\mu \mathrm{g} / \mathrm{ml})$

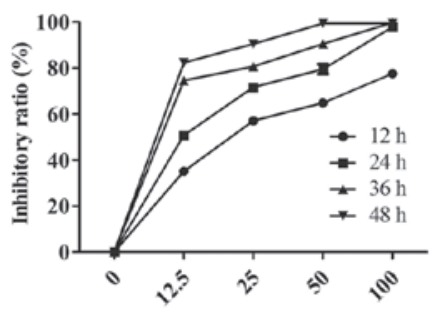

Concentration of cisplatin $(\mu \mathrm{g} / \mathrm{ml})$

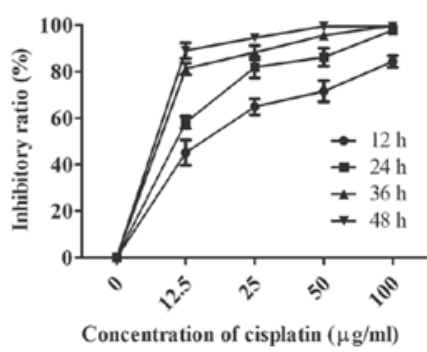

plus $25 \mu \mathrm{g} / \mathrm{ml}$ mangiferin

Figure 1. Mangiferin inhibits the proliferation of A549 cells. (A) Chemical structure of mangiferin. (B) Caco-2 colon carcinoma cells, HeLa cervical carcinoma cells, A549 non-small cell lung cancer cells, HepG2 and 7721 hepatocellular carcinoma cells, MCF-7 breast carcinoma cells, A375 melanoma cells and U87 glioblastoma cells were treated with various concentrations of mangiferin for $24 \mathrm{~h}$, and the half maximal inhibitory concentration $\left(\mathrm{IC}_{50}\right)$ values were quantified by MTT assay. ${ }^{*} \mathrm{P}<0.05$, mangiferin-treated A549 cell group vs the mangiferin-treated Caco- 2 cell group and mangiferin-treated 7721 cell group; ${ }^{*} \mathrm{P}<0.01$, mangiferin-treated A549 cell group vs. all other groups. Data are presented as the mean \pm standard error of the mean $(n=3)$. (C) Inhibitory ratio of A549 cells treated with various concentration of mangiferin (left panel), cisplatin (middle panel) and cisplatin $+25 \mu \mathrm{g} / \mathrm{ml}$ mangiferin (right panel) was determined by MTT assay. Data are presented as the mean \pm standard error of the mean $(n=3)$ and analyzed by two-way ANOVA, $\mathrm{P}<0.001$.

A

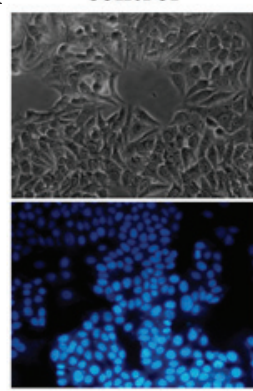

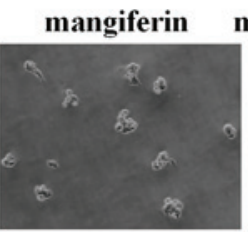

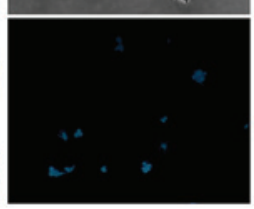

mangiferin + cisplatin

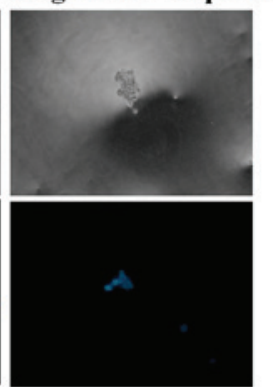

B
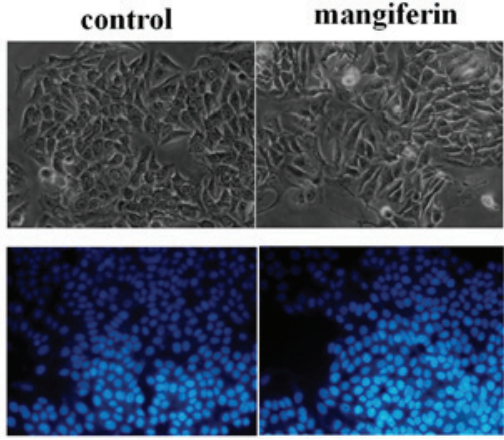

\section{C}

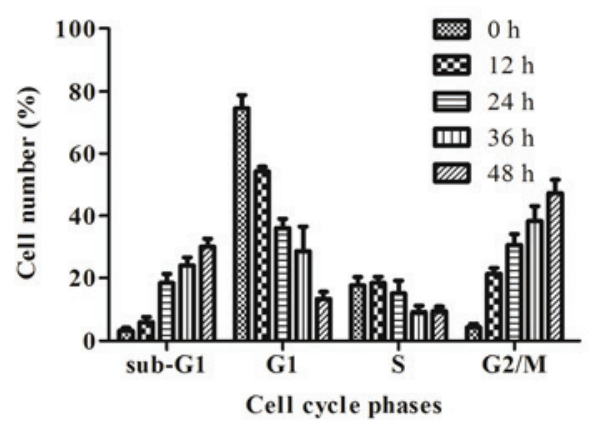

D

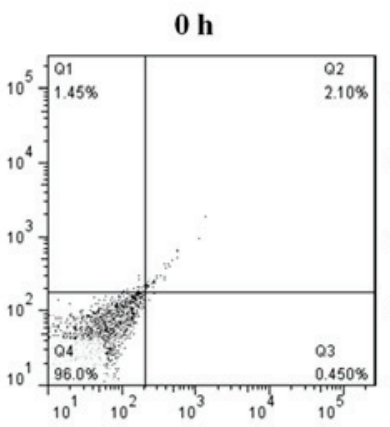

$12 \mathrm{~h}$

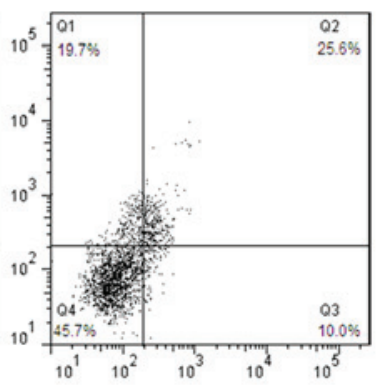

24 h

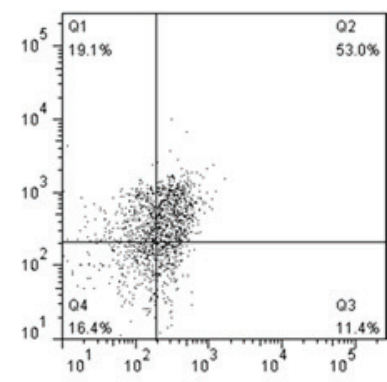

Figure 2. Mangiferin induces apoptosis and $\mathrm{G}_{2} / \mathrm{M}$ cell cycle arrest of A549 cells. (A) Apoptotic morphological observations of A549 cells treated with dimethyl sulfoxide, $25 \mu \mathrm{g} / \mathrm{ml}$ mangiferin, or mangiferin plus $16 \mu \mathrm{g} / \mathrm{ml}$ cisplatin under phase-contrast microscopy (magnification, 200x) (upper channel). A549 cells treated with PBS, $50 \mu \mathrm{g} / \mathrm{ml}$ mangiferin, or mangiferin plus $16 \mu \mathrm{g} / \mathrm{ml}$ cisplatin, were stained with Hoechst 33342 and observed under fluorescence microscopy (magnification, 200x) (lower channel). (B) Apoptotic morphological observations of human embryonic lung fibroblast cells treated with PBS or $25 \mu \mathrm{g} / \mathrm{ml}$ mangiferin (magnification, x200; upper channel). Fluorescent staining of HELF cells treated with either PBS or $25 \mu \mathrm{g} / \mathrm{ml}$ mangiferin, (magnification, x200; lower channel). (C) Percentages of A549 cells within each phase of the cell cycle. The cells were treated with $25 \mu \mathrm{g} / \mathrm{ml} \mathrm{mangiferin}$ and were measured by flow cytometry. Data are presented as the mean \pm standard error of the mean $(n=3)$ and analyzed by two-way ANOVA, $P<0.001$. (D) A549 cells were treated with $25 \mu \mathrm{g} / \mathrm{ml}$ mangiferin for 0,12 or $24 \mathrm{~h}$, and the ratios of early apoptotic and late apoptotic cells were measured by flow cytometry using the Annexin V-fluorescein isothiocyanate/propidium iodide double staining assay. Q1, cell debri; Q, late apoptotic cells; Q3, early apoptotic cells; Q4, live cells. 


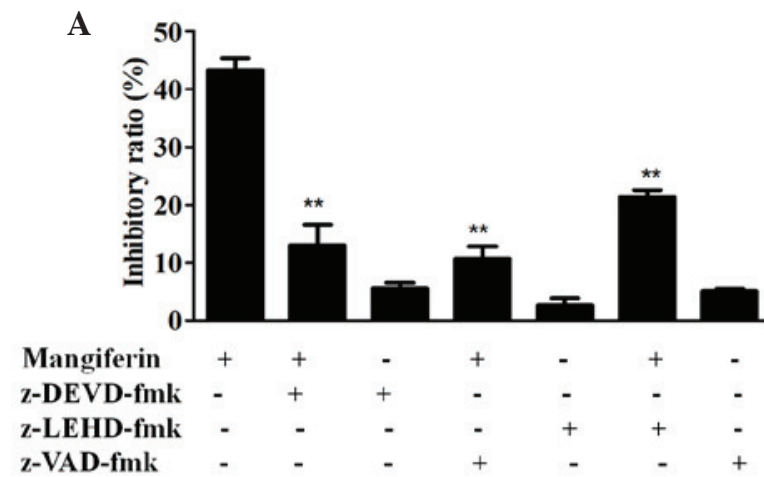

B
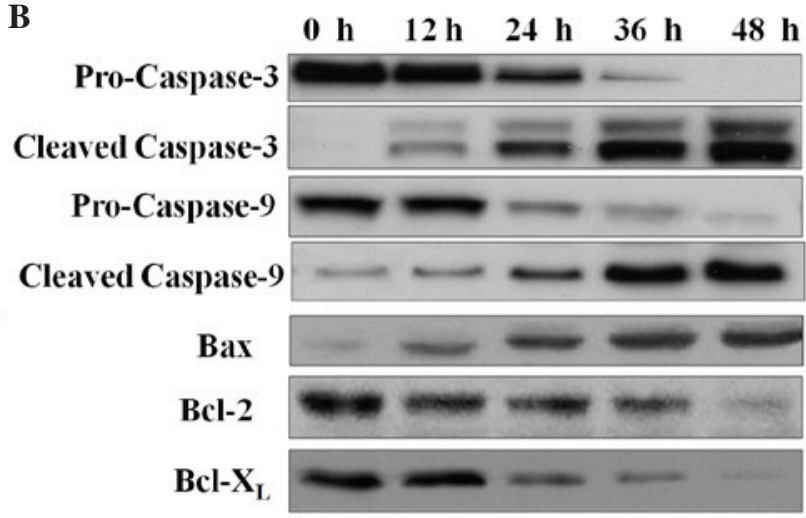

C

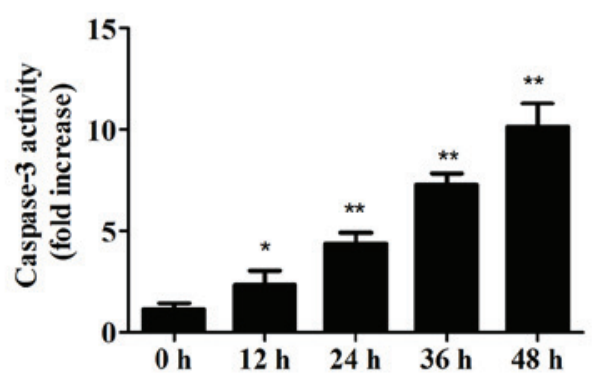

Cleaved PARP

$\beta$-actin

$\mathbf{E}$

$\mathbf{D}$

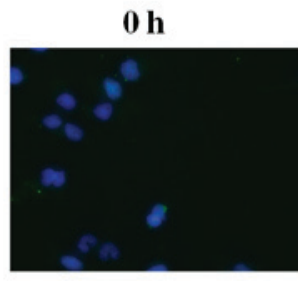

$12 \mathrm{~h}$

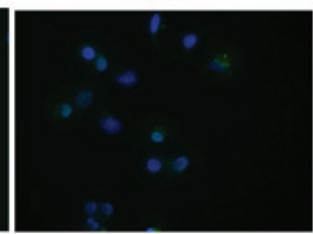

$24 \mathrm{~h}$

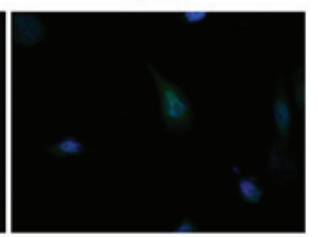

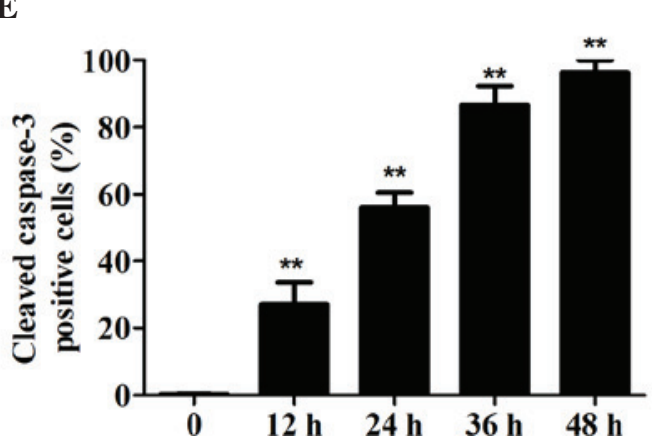

Figure 3. Mangiferin induces apoptosis via the caspase pathway. (A) Following pretreatment with or without $200 \mu \mathrm{M} z$-VAD-fmk (pan-caspase inhibitor), z-DEVD-fmk (caspase-3 inhibitor) and z-LEHD-fmk (caspase-9 inhibitor) for $2 \mathrm{~h}$, the growth inhibition of A549 cells treated with mangiferin for $24 \mathrm{~h}$ was determined. ${ }^{* *} \mathrm{P}<0.01$ vs. groups treated with caspase inhibitors but not with mangiferin. (B) Treatment with $25 \mu \mathrm{g} / \mathrm{ml} \mathrm{mangiferin}$ induced cleavage of caspase-3 and caspase-9. Mangiferin resulted in cleavage of poly ADP-ribose polymerase (PARP), upregulation of proapoptotic B-cell lymphoma (Bcl)-2-associated $\mathrm{X}$ (Bax), and downregulation of anti-apoptotic Bcl-2 and Bcl-extra large $\left(\mathrm{X}_{\mathrm{L}}\right)$ in a time-dependent manner. (C) Effects of $25 \mu \mathrm{g} / \mathrm{ml}$ mangiferin on caspase-3 activation with increasing time. ${ }^{*} \mathrm{P}<0.05$ and ${ }^{* *} \mathrm{P}<0.01$ vs. the $0 \mathrm{~h}$ group. (D) Immunofluorescent staining of cleaved caspase-3 indicated increased expression in the cytoplasm (magnification, x200). Green fluorescence, cleaved caspase-3-labeled cells; blue fluorescence, cell nuclei. Compared with 0 h cells, more apoptotic cells were observed and less cells survived following mangiferin treatment for $24 \mathrm{~h}$. (E) Statistical analysis of cleaved caspase-3-positive cells. ${ }^{* *} \mathrm{P}<0.01$ vs. the $0 \mathrm{~h}$ group. Data are presented as the mean \pm standard error of the mean $(\mathrm{n}=3)$.

the cells was increased, thus indicating that cytochrome $c$ was released from the mitochondria (Fig. 4B). These results clearly indicate that mangiferin-induced apoptosis in A549 cells may be mediated via the mitochondrial pathway.

Mangiferin induces apoptosis in A549 cells via inhibition of the PKC-NF- $\mathrm{B} B$ pathway. To further explore the mechanism underlying mangiferin-induced apoptosis in A549 cells, A549 cells were pretreated with the PKC inhibitor staurosporine or the NF- $\kappa \mathrm{B}$ inhibitor pyrrolidine dithiocarbamate (PDTC), and mangiferin-induced cell cytotoxicity was measured. As shown in Fig. 5A, these inhibitors significantly increased the mangiferin-induced inhibitory ratio and induced A549 cell survival. These results indicate that the PKC-NF- $\kappa$ B pathway may have a protective role in mangiferin-induced A549 cell apoptosis. To further verify that mangiferin-induced cell apoptosis was induced via inhibition of the $\mathrm{PKC}-\mathrm{NF}-\kappa \mathrm{B}$ pathway, the protein expression levels of $\mathrm{PKC}$ and $\mathrm{NF}-\kappa \mathrm{B}$ were quantified by western blotting. As shown in Fig. 5B, A549 cells treated with mangiferin exhibited downregulated $\mathrm{PKC}$ and $\mathrm{NF}-\kappa \mathrm{B}$ protein expression.
Mangiferin induces $G_{2} / M$ phase cell-cycle arrest by downregulating the cdc2-cyclin B1 signaling pathway. To determine whether the cdc2-cyclin B1 signaling pathway was involved in mangiferin-induced cell cycle arrest, and whether the cdc2-cyclin B1 signaling pathway was downregulated or upregulated, A549 cells were treated with $25 \mu \mathrm{g} / \mathrm{ml}$ mangiferin for various time periods. The mangiferin-treated cells and control cells were collected, fixed and quantified by flow cytometry. Analysis of the cell cycle distribution demonstrated that, as compared with that of the control group, treatment of A549 cells with mangiferin resulted in an increase in the percentage of $\mathrm{G}_{2} / \mathrm{M}$ phase cells. This result indicates that mangiferin may induce $\mathrm{G}_{2} / \mathrm{M}$ phase arrest (Fig. 2C). Furthermore, to explore the mechanism underlying mangiferin-induced cell cycle arrest, western blotting of cell cycle regulatory proteins, such as cyclin B1 and cdc2 was performed. As shown in Fig. 5B, treatment of A549 cells with mangiferin resulted in decreased protein expression levels of cyclin B1 and cdc2. These results indicate that mangiferin may induce $G_{2} / M$ phase cell cycle arrest by downregulating the expression levels of cdc 2 and cyclin B1. 
A

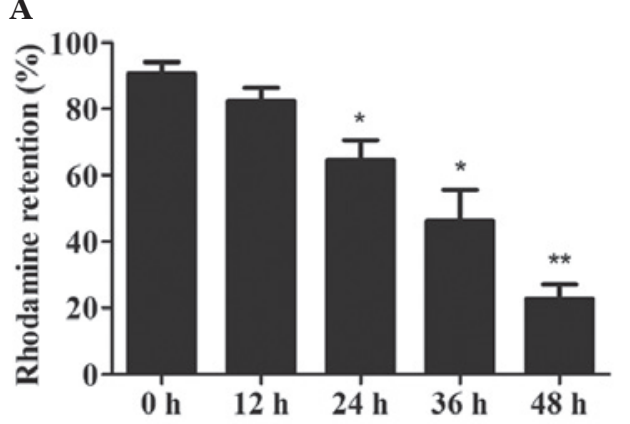

B

Cyto.c. (mito.)

$\begin{array}{lllll}0 & 12 \mathrm{~h} & 24 \mathrm{~h} & 36 \mathrm{~h}\end{array}$

$48 \mathrm{~h}$

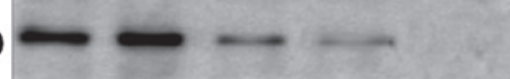

12 kDa

Prohibitin

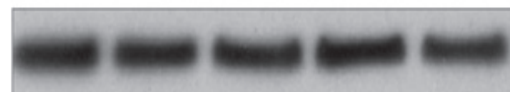

$30 \mathrm{kDa}$

Cyto.c. (cyto.)

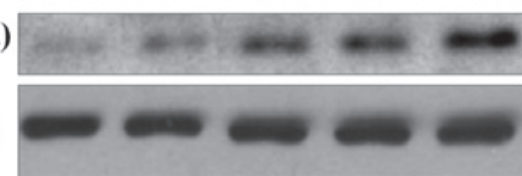

12 kDa

$46 \mathrm{kDa}$

Figure 4. Mangiferin induces apoptosis via the mitochondrial pathway. (A) Following treatment with $25 \mu \mathrm{g} / \mathrm{ml} \mathrm{mangiferin}$ for various time periods, the cells were loaded with $1 \mu \mathrm{g} / \mathrm{ml}$ rhodamine- 123 at $37^{\circ} \mathrm{C}$ for $15 \mathrm{~min}$ and analyzed by flow cytometry. (B) Cell lysates were fractionated to isolate the cytoplasm and crude mitochondria. The presence of cytochrome $c$ (cyto.c.) in the cytoplasm (cyto.) and mitochondrial (mito.) fractions was assessed by western blot analysis using the ApoTrack antibody cocktail. $\beta$-actin was used as cytoplasm equal loading control, and prohibitin was used as mitochondria loading control. Data are presented as the mean \pm standard error of the mean $(n=3)$. ${ }^{*} \mathrm{P}<0.05$ and ${ }^{* *} \mathrm{P}<0.01$ vs. the 0 h group.

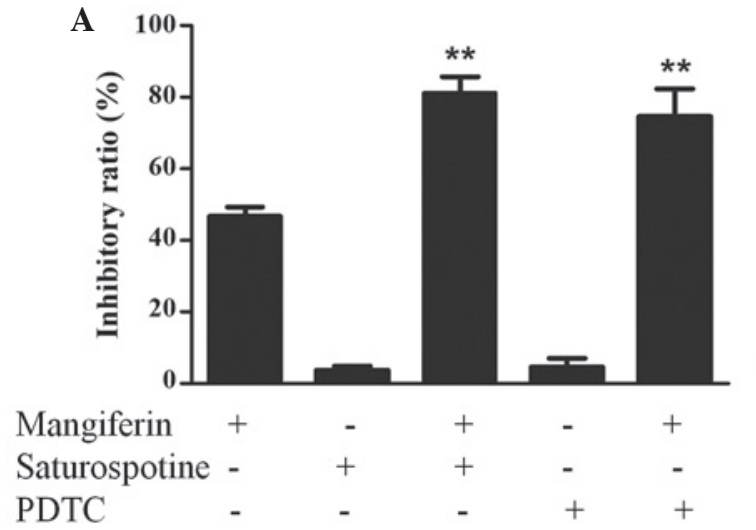

B

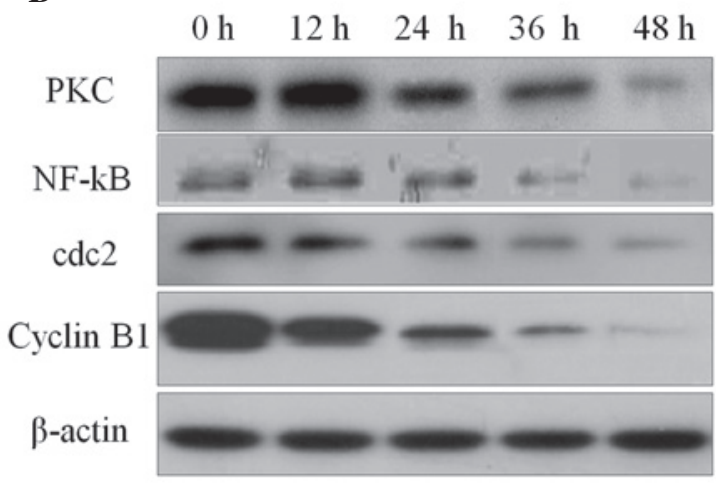

Figure 5. Molecular mechanism underlying mangiferin-induced $\mathrm{G}_{2} / \mathrm{M}$ phase cell cycle arrest and apoptosis. (A) A549 cells were pretreated with the protein kinase $\mathrm{C}(\mathrm{PKC})$ inhibitor staurosporine, or the nuclear factor (NF)- $\mathrm{kB}$ inhibitor pyrrolidine dithiocarbamate (PDTC), and mangiferin-induced cell growth inhibitory ratios were measured. (B) Cells were treated with $25 \mu \mathrm{g} / \mathrm{ml}$ mangiferin for various durations, and the expression levels of PKC, NF- $\mathrm{kB}$, cyclin B1 and cyclin-dependent kinase 1 (cdc2) were detected by western blot analysis. $\beta$-actin was used as an equal loading control. Data are presented as the mean \pm standard error of the mean $(\mathrm{n}=3)$. ). ${ }^{* *} \mathrm{P}<0.01$ vs. the group treated with inhibitor and but not with mangiferin.

Xenograft tumor growth is inhibited following mangiferin administration in vivo. To determine whether mangiferin administration exhibited an antitumor effect in vivo, an A549 xenograft mouse model was generated. A549 cells were inoculated into the neck of nude mice, and mangiferin was administered for 2 weeks. Prior to and after mangiferin treatment, mouse body weight was measured daily. Subsequently, 5 mice in each group were sacrificed, and 5 mice in each group were raised for survival assay. Following sacrifice, the subcutaneous tumors were harvested and weighed. Three dimensional tumor volume was determined using vernier calipers, and relative tumor volume was calculated as the tumor volume of the mangiferin-treated group divided by the tumor volume of the blank control group. As shown in Fig. 6A, after 14 days of treatment, xenograft tumor volume was significantly decreased in the mangiferin-treated group in a dose-dependent manner, as compared with in the blank control group. Furthermore, calculation of the relative volume demonstrated that $100 \mathrm{mg} / \mathrm{kg}$ mangiferin exhibited similar effects on tumor inhibition to cisplatin, which reached $\sim 90 \%$ (Fig. 6B). These results indicate that mangiferin may be considered a potential effective antitumor agent.
Further in vivo studies were performed; including survival assay and body weight assessment, and the inhibitory ratio was calculated (Table I). As shown in Fig. 6C, compared with the blank control group, mangiferin markedly prolonged the lifespan of A549 cell xenograft mice. Untreated mice (blank control) succumbed within 40 days of A549 inoculation; however, mangiferin or cisplatin (positive control) treatment significantly increased the lifespan of xenograft mice. Even low dose treatment $(10 \mathrm{mg} / \mathrm{kg})$ could partially rescue A549-inoculated mice, and $>60 \%$ of mice survived until the end of the in vivo assay. Furthermore, high dose mangiferin treatment $(100 \mathrm{mg} / \mathrm{kg})$ could significantly increase the lifespan of xenograft mice, as compared with the cisplatin-treated mice. In addition, there was a significant difference between high dose mangiferin-treated mice and cisplatin-treated mice $(\mathrm{P}<0.05)$. Assessment of body weight demonstrated that following treatment with various doses of mangiferin for 14 days, the weight of the mice was markedly decreased (Fig. 6D; $\mathrm{P}<0.05$ ). In addition, the body weight of $100 \mathrm{mg} / \mathrm{kg}$ mangiferin-treated mice almost reached that of the cisplatin-treated mice. Based on the survival ratio and body weight data, these results indicate that mangiferin may exhibit antitumor activity in vivo. 
Table I. Inhibitory effects of mangiferin on A549-bearing mice after 14 days $(\mathrm{n}=10, \mathrm{P}<0.05)$.

\begin{tabular}{lcccc}
\hline Group & Volume/cm & Volume inhibition & Weight/g & $\begin{array}{c}\text { Weight inhibition } \\
\text { rate }(\%)\end{array}$ \\
\hline Blank control & $0.57 \pm 0.29$ & $0.93 \pm 0.28$ & & \\
$10 \mathrm{mg} / \mathrm{kg}$ & $0.43 \pm 0.14$ & $0.74 \pm 0.35$ & 23.9 & 18.3 \\
$50 \mathrm{mg} / \mathrm{kg}$ & $0.28 \pm 0.19^{\mathrm{a}}$ & $0.61 \pm 0.19^{\mathrm{b}}$ & 29.5 & 42.7 \\
$100 \mathrm{mg} / \mathrm{kg}$ & $0.12 \pm 0.06^{\mathrm{b}}$ & $0.38 \pm 0.12^{\mathrm{b}}$ & 71.3 & 62.3 \\
Positive control & $0.09 \pm 0.09^{\mathrm{c}}$ & $0.27 \pm 0.09^{\mathrm{c}}$ & $80.6 \mathrm{P}$ & 75.8 \\
\hline
\end{tabular}

Data are presented as the mean \pm standard error of the mean. ${ }^{\mathrm{a}} \mathrm{P}<0.05,{ }^{\mathrm{b}} \mathrm{P}<0.01,{ }^{\mathrm{c}} \mathrm{P}<0.001 \mathrm{vs}$. the blank control group.
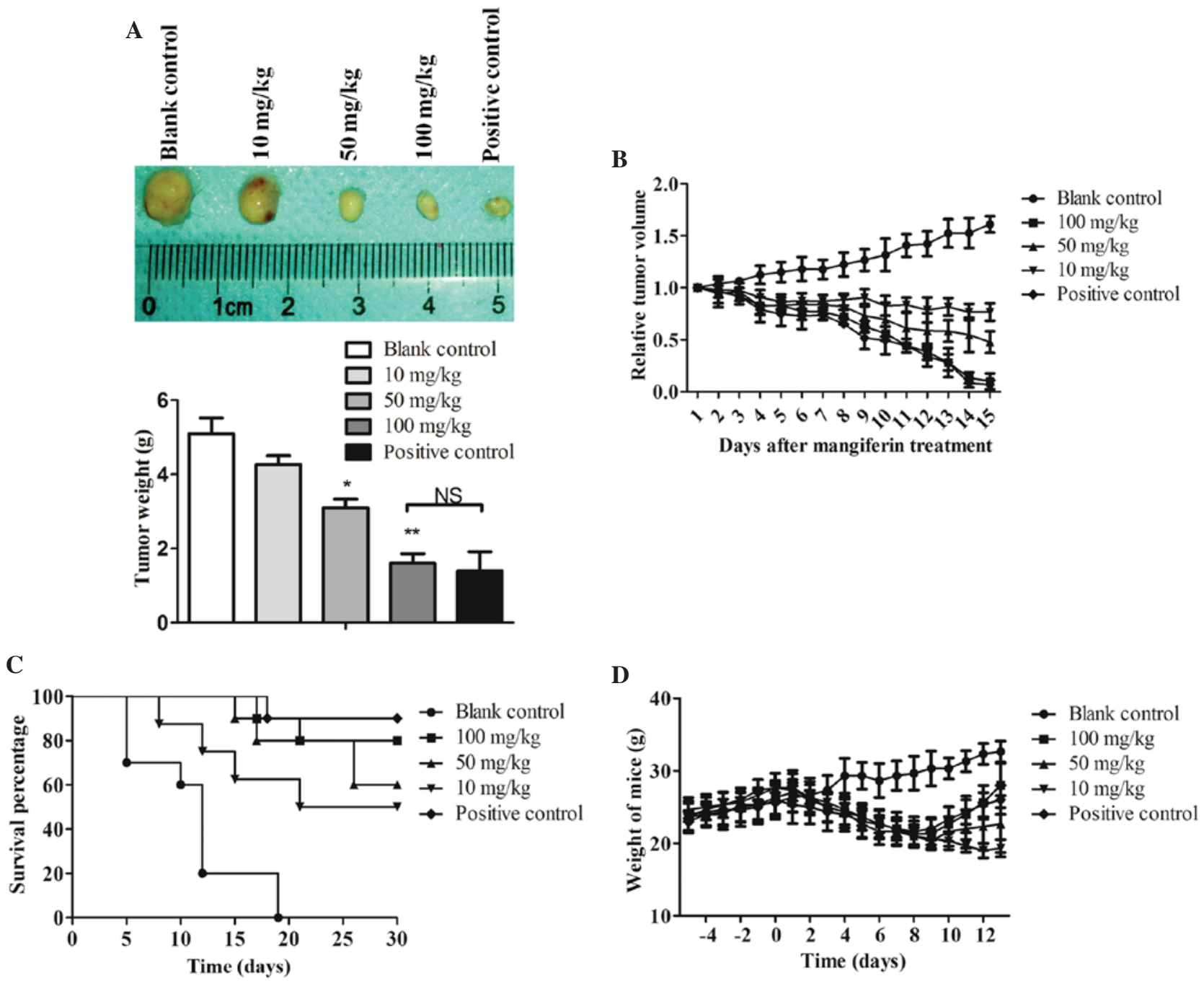

Figure 6. Mangiferin inhibits xenograft tumor growth in vivo. (A) Image of xenograft tumors treated with phosphate-buffered saline (blank control), various doses of mangiferin, and positive control (upper panel). The tumor weight of the mice from each group are presented in the lower panel. ${ }^{*} \mathrm{P}<0.05$ and ${ }^{* *} \mathrm{P}<0.01$, vs. the blank control group. (B) Relative tumor volume of each group following mangiferin treatment $(n=10, P<0.05)$ analyzed by two-way ANOVA. (C) Survival curve of A549 cell xenograft mice following treatment with various doses of mangiferin $(n=10, P<0.05)$ analyzed by Kaplan-Meier analysis of survival. (D) Weight of A549 cell xenograft mice treated with various doses of mangiferin $(n=10, P<0.05)$ analyzed by two-way ANOVA. Data are presented as the mean \pm standard error of the mean.

\section{Discussion}

The present study investigated mangiferin-induced apoptosis of A549 human lung adenocarcinoma cells with the hope of identifying a therapeutic strategy for the treatment of cancer. Mangiferin has recently gained more attention due to its comparatively various biological functions. In the present study, mangiferin exerted growth-inhibitory and apoptosis-inducing effects on A549 lung adenocarcinoma cells in vitro and in vivo. Further experiments regarding 
the mechanism underlying mangiferin-induced A549 cell apoptosis demonstrated that, firstly, mangiferin was able to induce A549 lung adenocarcinoma cell arrest at $\mathrm{G}_{2} / \mathrm{M}$ phase by downregulating the cdc2-cyclin B1 signaling pathway. Secondly, mangiferin was able to induce the apoptosis of A549 cells by inhibiting the PKC-NF- $\kappa$ B pathway. Finally, mangiferin exerted anticancer and apoptosis-inducing effects in vivo, as detected by decreases in the volume and weight of the subcutaneous tumor mass, and the enhanced lifespan of the mice.

Previous studies have reported the anticancer effects of mangiferin. Mangiferin has been shown to inhibit tumor necrosis factor-induced activation of $\mathrm{NF}-\kappa \mathrm{B}$ in A549 cells (18). In addition, crude extract of mangiferin suppressed MDA-MB-231 cell proliferation by inhibiting the NF- $\kappa$ B pathway in A549 cells (5). Administration of mangiferin was also able to enhance the detoxification of enzymes, including glutathione transferase, quinone reductase and uridin 5'-diphosphate-glucuronosyl transferase, and reduce DNA damage in lung cancer-bearing animals (19). In addition, mangiferin has been reported to inhibit telomerase activity and induce apoptosis in K562 cells $(8,9)$, and Mangifera indica extract initiated $\mathrm{G}_{0} / \mathrm{G}_{1}$ phase cell cycle arrest (10).

In the present study, mangiferin was shown to induce intrinsic mitochondrial-mediated apoptosis in a caspase-3 and caspase- 9 dependent manner. As determined using caspase-3 activity assays and the analysis of cleaved caspase-3 immunostaining in A549 cells, mangiferin induced apoptosis via the caspase pathway. The release of cytochrome $c$ from the mitochondria to the cytoplasm appears to be a central event in apoptosis, since it is critical for the initiation of the caspase family (16). Cytochrome $c$ expression was detected in the cytosol and mitochondria using western blotting, and the results indicated that alongside reduced mitochondrial membrane potential, cytochrome $c$ release from the mitochondria into the cytosol was increased following treatment with mangiferin. These results suggested that treatment with mangiferin resulted in activation of caspase-3 and -9 , release of cytochrome $c$ into the cytoplasm, reduced mitochondrial membrane potential, upregulated proapoptotic Bax, downregulated anti-apoptotic $\mathrm{Bcl}-2$ and $\mathrm{Bcl}-\mathrm{X}_{\mathrm{L}}$, and cleavage of PARP, which are characteristics of caspase- and mitochondrial-dependent apoptosis.

Subsequent studies regarding the cell cycle progression of A549 cells demonstrated that the percentage of cells within $\mathrm{G}_{2} / \mathrm{M}$ and sub- $\mathrm{G}_{1}$ phase were markedly increased in response to mangiferin treatment in a time-dependent manner. These results indicated that mangiferin was able to induce $G_{2} / M$ phase cell cycle arrest and apoptotic cell death in A549 cells. Previous studies on cell cycle proteins have reported that in various tumors, the cdc2-cyclin B1 complex is overexpressed (20-22). Therefore, suppressing expression of the cdc2-cyclin B1 complex may result in cancer cell growth inhibition (23). In eukaryotes, initiation of the cdc2-cyclin B1 complex (M-phase promoting factor, MPF) has an important role in regulating the entry into mitosis, and cdc2 is known to be an active sub-unit of MPF (24). Therefore, in the present study, the protein expression levels of cdc 2 and cyclin B1 were investigated, and the results demonstrated that following treatment with $25 \mu \mathrm{g} / \mathrm{ml}$ mangiferin for 12 , 24, 36 and $48 \mathrm{~h}$, the expression levels of cdc 2 and cyclin B1 were decreased. These results suggested that mangiferin was able to inhibit A549 human lung carcinoma cell proliferation by initiating $\mathrm{G}_{2} / \mathrm{M}$ cell cycle arrest via downregulation of the cdc2-cyclin B1 signaling pathway.

Further exploration of the molecular mechanisms underlying mangiferin-induced apoptosis indicated that mangiferin initiated apoptotic cell death via suppression of the PKC-NF- $\kappa$ B pathway. $\mathrm{PKC} \varepsilon$ is an oncogenic kinase, which is essential for cell survival regulation, mitogenesis and invasion, and PKCE is upregulated in the majority of epithelial cancers, including prostate and lung cancer (25). In addition, a strong correlation has been detected between PKC overexpression and $\mathrm{NF}-\kappa \mathrm{B}$ activation, and the NF- $\mathrm{NB}$ family of transcription factors has a crucial role in inflammation, as well as in regulation of the expression of genes involved in cell survival, proliferation, angiogenesis and invasion (26). Therefore, in the present study, after pretreatment of A549 cells with the PKC inhibitor staurosporine and the NF- $\mathrm{NB}$ inhibitor PDTC, mangiferin-induced cytotoxicity was investigated and was shown to be markedly increased. These findings indicated that PKC and NF- $\kappa \mathrm{B}$ have a protective role in mangiferin-induced A549 cell apoptosis. This result was further demonstrated by western blotting, the protein expression levels of $\mathrm{PKC}$ and $\mathrm{NF}-\kappa \mathrm{B}$ were markedly decreased in a time-dependent manner, indicating that mangiferin induced apoptosis via suppression of the PKC-NF- $\kappa \mathrm{B}$ signaling pathway in A549 human lung carcinoma cells. Thereby, inhibition of the PKC-NF- $\kappa \mathrm{B}$ pathway may function as an effective strategy in cancer treatment.

As well as investigating the in vitro anti-cancer activity of mangiferin, mangiferin was verified to possess antitumor effects in vivo. Treatment with mangiferin was able to decrease the volume and weight of subcutaneous tumor mass; after 14 days of treatment tumor volume and weight decreased by $\sim 90$ and $85 \%$, respectively. The highest dose of mangiferin $(100 \mathrm{mg} / \mathrm{kg})$ exhibited similar antitumor effects to cisplatin, which serves as an accepted effective antitumor agent. These results indicated that mangiferin may possess the potential to inhibit A549 human lung carcinoma cell growth and induce apoptotic cell death in vitro and in vivo.

In conclusion, the results of the present study provided evidence regarding the antitumor effects and underlying mechanisms of mangiferin in A549 cells, and sheds new light on the application of mangiferin in human lung adenocarcinoma therapy. The present study is the first, to the best of our knowledge, to report that mangiferin induced $\mathrm{G}_{2} / \mathrm{M}$ phase cell cycle arrest via the cdc2-cyclin B1 pathway, and induced cell apoptosis via the PKC-NF- $\kappa \mathrm{B}$ pathway. Due to the gradual elucidation of the molecular mechanisms underlying the antitumor activities of mangiferin, novel therapeutic strategies may be developed that target cell apoptotic pathways for cancer therapy.

\section{Acknowledgements}

The present study was supported in part by the National Natural Science Foundation of China (grant nos. 81271049 and 30871350), Guangxi Education funding (grant no. 2015-12) and Key Laboratory Funding (grant no. 12-071-08). 


\section{References}

1. Sánchez GM, Re L, Giuliani A, Núñez-Sellés AJ, Davison GP and León-Fernández OS: Protective effects of Mangifera indica L. extract, mangiferin and selected antioxidants against TPA-induced biomolecules oxidation and peritoneal macrophage activation in mice. Pharmacol Res 42: 565-573, 2000.

2. Dar A, Faizi S, Naqvi S, Roome T, Zikr-ur-Rehman S, Ali M, Firdous S and Moin ST: Analgesic and antioxidant activity of mangiferin and its derivatives: The structure activity relationship. Biol Pharm Bull 28: 596-600, 2005.

3. Guha S, Ghosal S and Chattopadhyay U: Antitumor, immunomodulatory and anti-HIV effect of mangiferin, a naturally occurring glucosylxanthone. Chemotherapy 42: 443-451, 1996.

4. Duang XY, Wang Q, Zhou XD and Huang DM: Mangiferin: A possible strategy for periodontal disease to therapy. Med Hypotheses 76: 486-488, 2011.

5. García-Rivera D, Delgado R, Bougarne N, Haegeman G and Berghe WV: Gallic acid indanone and mangiferin xanthone are strong determinants of immunosuppressive anti-tumour effects of Mangifera indica L. bark in MDA-MB231 breast cancer cells. Cancer Lett 305: 21-31, 2011.

6. Noratto GD, Bertoldi MC, Krenek K, Talcott ST, Stringheta PC and Mertens-Talcott SU: Anticarcinogenic effects of polyphenolics from mango (Mangifera indica) varieties. J Agric Food Chem 58: 4104-4112, 2010.

7. Chieli E, Romiti N, Rodeiro I and Garrido G: In vitro effects of Mangifera indica and polyphenols derived on ABCB1/P-glycoprotein activity. Food Chem Toxicol 47: 2703-2710, 2009.

8. Cheng P, Peng ZG, Yang J and Song SJ: The effect of mangiferin on telomerase activity and apoptosis in leukemic K562 cells. Zhong Yao Cai 30: 306-309, 2007 (In Chinese).

9. Peng ZG, Luo J, Xia LH, Chen Y and Song SJ: CML cell line K562 cell apoptosis induced by mangiferin. Zhongguo Shi Yan Xue Ye Xue Za Zhi 12: 590-594, 2004 (In Chinese).

10. Percival SS, Talcott ST, Chin ST, Mallak AC, Lounds-Singleton A and Pettit-Moore J: Neoplastic transformation of BALB/3T3 cells and cell cycle of HL-60 cells are inhibited by mango (Mangifera indica L.) juice and mango juice extracts. J Nutr 136: 1300-1304, 2006.

11. Chari NS, Pinaire NL, Thorpe L, Medeiros LJ, Routbort MJ and McDonnell TJ: The p53 tumor suppressor network in cancer and the therapeutic modulation of cell death. Apoptosis 14: 336-347, 2009.

12. Hanahan D and Weinberg RA: Hallmarks of cancer: The next generation. Cell 144: 646-674, 2011.

13. Hartwell LH and Kastan MB: Cell cycle control and cancer. Science 266: 1821-1828, 1994
14. Vermeulen K, Van Bockstaele DR and Berneman ZN: The cell cycle: A review of regulation, deregulation and therapeutic targets in cancer. Cell Prolif 36: 131-149, 2003.

15. Malumbres $M$ and Barbacid M: Cell cycle, CDKs and cancer: A changing paradigm. Nat Rev Cancer 9: 153-166, 2009.

16. Goldstein JC, Waterhouse NJ, Juin P, Evan GI and Green DR: The coordinate release of cytochrome $c$ during apoptosis is rapid, complete and kinetically invariant. Nat Cell Biol 2: 156-162, 2000

17. Li CY, Wang Y, Wang HL, Shi Z, An N, Liu YX, Liu Y, Zhang J, Bao JK and Deng SP: Molecular mechanisms of Lycoris aurea agglutinin-induced apoptosis and G2/M cell cycle arrest in human lung adenocarcinoma A549 cells, both in vitro and in vivo. Cell Prolif 46: 272-282, 2013.

18. Sarkar A, Sreenivasan Y, Ramesh GT and Manna SK: beta-D-Glucoside suppresses tumor necrosis factor-induced activation of nuclear transcription factor kappaB but potentiates apoptosis. J Biol Chem 279: 33768-33781, 2004.

19. Rajendran P, Ekambaram G and Sakthisekaran D: Protective role of mangiferin against Benzo(a)pyrene induced lung carcinogenesis in experimental animals. Biol Pharm Bull 31: 1053-1058, 2008.

20. Touny LH and Banerjee PP: Identification of both Myt-1 and Wee-1 as necessary mediators of the p21-independent inactivation of the cdc-2/cyclin B1 complex and growth inhibition of TRAMP cancer cells by genistein. Prostate 66: 1542-1555, 2006.

21. Hoffmann TK, Trellakis S, Okulicz K, Schuler P, Greve J, Arnolds J, Bergmann C, Bas M, Lang S, Lehnerdt G, et $a l$ : Cyclin B1 expression and p53 status in squamous cell carcinomas of the head and neck. Anticancer Res 31: 3151-3157, 2011.

22. Chen H, Huang Q, Dong J, Zhai DZ, Wang AD and Lan Q: Overexpression of CDC2/CyclinB1 in gliomas, and CDC2 depletion inhibits proliferation of human glioma cells in vitro and in vivo. BMC Cancer 8: 29, 2008.

23. Vairapandi M, Balliet AG, Hoffman B and Liebermann DA: GADD 45b and GADD45g are cdc2/cyclinB1 kinase inhibitors with a role in S and G2/M cell cycle checkpoints induced by genotoxic stress. J Cell Physiol 192: 327-338, 2002.

24. Chen H, Huang Q, Dong J, Zhai DZ, Wang AD and Lan Q: Overexpression of CDC2/CyclinB1 in gliomas, and CDC2 depletion inhibits proliferation of human glioma cells in vitro and in vivo. BMC Cancer 8: 29, 2008.

25. Reyland ME: Protein kinase Cdelta and apoptosis. Biochem Soc Trans 35: 1001-1004, 2007.

26. Mezzano S, Aros C, Droguett A, Burgos ME, Ardiles L, Flores C, Schneider H, Ruiz-Ortega M and Egido J: NF-kappaB activation and overexpression of regulated genes in human diabetic nephropathy. Nephrol Dial Transplant 19: 2505-2512, 2004. 